\title{
Predicting the Emission Rate of Volatile Organic Compounds from Vinyl Flooring
}

Steven S. Cox ${ }^{1}$, John C. Little ${ }^{* 1}$, Alfred T. Hodgson ${ }^{2}$

${ }^{1}$ Virginia Polytechnic Institute \& State University, 418 Durham Hall, Blacksburg, VA 24061

${ }^{2}$ E.O. Lawrence Berkeley National Laboratory, 1 Cyclotron Road, Berkeley, CA 94720

\begin{abstract}
A model for predicting the rate at which a volatile organic compound (VOC) is emitted from a diffusion-controlled material is validated for three contaminants (n-pentadecane, $n$-tetradecane, and phenol) found in vinyl flooring (VF). Model parameters are the initial VOC concentration in the material-phase $\left(\mathrm{C}_{0}\right)$, the material/air partition coefficient $(\mathrm{K})$, and the material-phase diffusion coefficient (D). The model was verified by comparing predicted gas-phase concentrations to data obtained during small-scale chamber tests, and by comparing predicted material-phase concentrations to those measured at the conclusion of the chamber tests. Chamber tests were conducted with the VF placed top side up and bottom side up. With the exception of phenol, and within the limits of experimental precision, the mass of VOCs recovered in the gas phase balances the mass emitted from the material phase. The model parameters $\left(\mathrm{C}_{0}, \mathrm{~K}\right.$, and $\left.\mathrm{D}\right)$ were measured using procedures that were completely independent of the chamber test. Gas- and material-phase predictions compare well to the bottom-side-up chamber data. The lower emission rates for the top-side-up orientation may be explained by the presence of a low-permeability surface layer. The sink effect of the stainless steel chamber surface was shown to be negligible.
\end{abstract}

*Corresponding author telephone: (540) 231-8737; fax: (540) 231-7916; email: jcl@ vt.edu 


\section{Introduction}

Various building materials and consumer products (examples include adhesives, sealants, paints, wood stain, carpets, vinyl flooring, and manufactured wood products) are sources of volatile organic compounds (VOCs) in the indoor environment. These materials typically contain residual quantities of VOCs that can be important sources of air contamination. Understanding the source characteristics of these materials is crucial if indoor air quality problems are to be solved (1). For example, an improved understanding of mass transfer mechanisms could facilitate the reformulation of building materials to minimize VOC contamination of indoor air (2).

Characterizing the source behavior of building materials typically involves chamber studies, which are time-consuming, costly, and subject to several limitations (3). Of the various mechanisms governing VOC source behavior, diffusion is one of the most important (4). Chamber-based source characterization studies have frequently neglected the role of diffusion in emission processes. Furthermore, models based on chamber-derived data are often empirical in nature and are of limited value when extrapolating to other conditions. For those indoor sources that are controlled by internal diffusion processes, a mechanistic diffusion model holds considerable promise for predicting emission characteristics when compared to empirical models $(3,4,5)$. The parameters for the diffusion model are the initial concentration of VOC in the material $\left(\mathrm{C}_{0}\right)$, the material/air partition coefficient $(\mathrm{K})$, and the material-phase diffusion coefficient (D).

The primary objective of this study is to demonstrate that VOC emissions from vinyl flooring (VF), an exemplary diffusion-controlled source, are governed by well-established mass transfer principles and are predictable using a simple mathematical model. A secondary 
objective is to examine whether adsorption to the stainless-steel chamber surface represents a significant VOC sink.

\section{Emissions Model}

A model describing emissions from a homogeneous, diffusion-controlled source $(3,4,5)$ is briefly reviewed, and then extended to include the chamber wall sink effect. With reference to Figure 1, the transient diffusion equation is

$$
\frac{\partial \mathrm{C}}{\partial \mathrm{t}}=\mathrm{D} \frac{\partial^{2} \mathrm{C}}{\partial \mathrm{x}^{2}}
$$

where $\mathrm{C}$ is the concentration of a VOC in the slab of material (in this case, VF), D is the material-phase concentration-independent diffusion coefficient, $\mathrm{t}$ is time, and $\mathrm{x}$ is distance from the base of the slab. The initial condition assumes a uniform concentration of the VOC, $\mathrm{C}_{0}$. The first boundary condition assumes there is no flux from the base of the slab. The second boundary condition is imposed via a mass balance on the VOC in the chamber air, or

$$
\frac{\partial \mathrm{y}}{\partial \mathrm{t}} \mathrm{V}=\mathrm{Q} \cdot \mathrm{y}_{\mathrm{in}}-\left.\mathrm{D} \cdot \mathrm{A} \frac{\partial \mathrm{C}}{\partial \mathrm{x}}\right|_{\mathrm{x}=\mathrm{L}}-\mathrm{Q} \cdot \mathrm{y}
$$

where $y_{\text {in }}$ and $y$ are the concentrations of the VOC in the influent and effluent chamber air, respectively, $\mathrm{Q}$ is the volumetric air flow rate, $\mathrm{V}$ is the well-mixed chamber volume, $\mathrm{A}$ is the exposed surface area of the slab, and $\mathrm{L}$ is the thickness of the slab. A linear and instantaneously reversible equilibrium relationship is assumed to exist between the slab surface and the chamber air, or

$$
\mathrm{K}=\frac{\left.\mathrm{C}\right|_{\mathrm{x}=\mathrm{L}}}{\mathrm{y}}
$$

where $\mathrm{K}$ is the material/air partition coefficient. Combining Equations 2 and 3 and assuming that $\mathrm{y}_{\text {in }}$ is zero, yields 


$$
\left.\left(\frac{\mathrm{V}}{\mathrm{A} \cdot \mathrm{K}}\right) \cdot \frac{\partial \mathrm{C}}{\partial \mathrm{t}}\right|_{\mathrm{X}=\mathrm{L}}+\left.\mathrm{D} \cdot \frac{\partial \mathrm{C}}{\partial \mathrm{x}}\right|_{\mathrm{X}=\mathrm{L}}+\left.\left(\frac{\mathrm{Q}}{\mathrm{A} \cdot \mathrm{K}}\right) \cdot \mathrm{C}\right|_{\mathrm{X}=\mathrm{L}}=0
$$

A solution to these equations (4) is:

$$
C(x, t)=2 C_{0} \sum_{n=1}^{\infty}\left\{\frac{\exp \left(-D q_{n}^{2} t\right)\left(h-k q_{n}^{2}\right) \cos \left(q_{n} x\right)}{\left[L\left(h-k q_{n}^{2}\right)^{2}+q_{n}^{2}(L+k)+h\right] \cos \left(q_{n} L\right)}\right\},
$$

where

$$
\begin{gathered}
\mathrm{h}=\frac{\mathrm{Q}}{\mathrm{ADK}} \\
\mathrm{k}=\frac{\mathrm{V}}{\mathrm{AK}}
\end{gathered}
$$

and the $\mathrm{q}_{\mathrm{n}} \mathrm{s}$ are the roots of

$$
\mathrm{q}_{\mathrm{n}} \tan \left(\mathrm{q}_{\mathrm{n}} \mathrm{L}\right)=\mathrm{h}-\mathrm{kq}_{\mathrm{n}}^{2}
$$

Equation (5) gives the contaminant concentration in the slab as a function of time and distance from the base of the slab. The gas-phase concentration of the VOC in the chamber at any time $t$ is obtained by first finding the concentration at the slab surface $(x=L)$ and then applying the equilibrium condition defined by Equation (3). Finding the roots of Equation (8) is straightforward because the function approaches infinity at well-defined intervals. The first root occurs between zero and $\pi /(2 \mathrm{~L})$, the second between $\pi /(2 \mathrm{~L})$ and $(3 \pi) /(2 \mathrm{~L})$, the third between $(3 \pi) /(2 \mathrm{~L})$ and $(5 \pi) /(2 \mathrm{~L})$, and so on. With the roots bracketed, they can be found using the method of bisection.

To evaluate the importance of the sink effect for a given VOC, a linear and instantaneously reversible equilibrium relationship is also assumed to exist between the stainless steel chamber surface and the chamber air, or

$$
\mathrm{K}_{\mathrm{s}}=\frac{\mathrm{q}}{\mathrm{y}}
$$


where $\mathrm{q}$ is the adsorbed surface concentration, and $\mathrm{K}_{\mathrm{s}}$ is the surface/air partition coefficient. With reference to Figure 1, $\mathrm{A}_{\mathrm{s}}$ is the exposed surface area of stainless steel within the chamber. Now, assuming that there is no VF in the chamber and that $y_{\text {in }}=0$, a mass balance on the VOC in the chamber (both adsorbed to the walls and in the gas-phase) yields

$$
\frac{\mathrm{dq}}{\mathrm{dt}} \mathrm{A}_{\mathrm{S}}+\frac{\mathrm{dy}}{\mathrm{dt}} \mathrm{V}=-\mathrm{Q} \cdot \mathrm{y} .
$$

If the gas-phase concentration in the chamber air at time zero is $\mathrm{y}_{0}$, then combining Equations 9 and 10 and integrating yields

$$
\ln \left(\frac{\mathrm{y}}{\mathrm{y}_{0}}\right)=-\left(\frac{\mathrm{Q}}{\mathrm{K}_{\mathrm{s}} \mathrm{A}_{\mathrm{s}}+\mathrm{V}}\right) \mathrm{t} .
$$

Equation 11 can be used to determine the value of $\mathrm{K}_{\mathrm{s}}$ from experimental data, as will be described. A similar analysis may also be applied to the situation where the VF slab is present in the chamber. In that case, Equation 2 must be modified to include the accumulation of the adsorbed VOC on the chamber walls, in an analogous fashion to Equation 10. Fortunately, as shown in Equation 11, the incorporation of the adsorbed phase may be expressed as a simple increase in the chamber volume equal in magnitude to $\mathrm{K}_{\mathrm{s}} \mathrm{A}_{\mathrm{s}}$. The foregoing solution may therefore be applied with Equation 7 modified as follows:

$$
\mathrm{k}=\frac{\mathrm{V}+\mathrm{K}_{\mathrm{S}} \mathrm{A}_{\mathrm{S}}}{\mathrm{AK}}
$$

\section{Experimental Approach}

A commercial grade sheet vinyl flooring material was selected for study because VF is present in many residential and commercial buildings, is relatively homogenous, and has been shown to emit hazardous organic chemicals (6). A small-scale chamber study was used to 
generate data for model validation. The model parameters $\left(\mathrm{C}_{0}, \mathrm{~K}\right.$, and $\left.\mathrm{D}\right)$ were measured completely independently of the chamber experiments. Additional experiments were conducted to measure the chamber surface partition coefficient, $\mathrm{K}_{\mathrm{s}}$. The model is validated by comparing experimental measurements to 1) the predicted gas-phase concentration in the chamber as a function of time during the chamber experiment, and 2) the predicted material-phase concentration in the VF as a function of depth after completion of the chamber experiments.

The VF used in this study was a monolayer sheet vinyl (1.8-m wide) manufactured for the medical facilities market. In addition to polyvinyl chloride (PVC), the VF contained approximately $50 \%$ (by weight) $\mathrm{CaCO}_{3}$ as well as plasticizers, pigments, and stabilizers (7). The nominal thickness was $2 \mathrm{~mm}$ with a density of approximately $1.5 \mathrm{~g} \mathrm{~cm}^{-3}$. The VF was manufactured four months prior to the investigation. Upon receipt, six $30 \mathrm{~cm} \times 30 \mathrm{~cm}$ squares were cut from the center of the specimen, stacked, wrapped in multiple layers of aluminum foil, and stored at below $-5^{\circ} \mathrm{C}$. Squares from the center of the stack were removed as needed for experimental work. Experiments were completed within two months of receipt of the specimen.

In all experiments, gas samples for VOCs were collected on Tenax ${ }^{\circledR}-\mathrm{TA}$ sorbent tubes. The tubes were analyzed for individual VOCs by thermal desorption gas chromatography/mass spectrometry using a modification of U.S. EPA Method TO-1. The target compounds were n-tetradecane, n-pentadecane, phenol, and 2,2,4-trimethyl-1,3-pentanediol monoisobutyrate (TMPD-MIB). Multi-point internal standard calibrations were prepared for all compounds. The VF was tested for VOC emissions in small-scale chambers following standard practice (8). The 10.5-L chambers were constructed of 316 stainless steel and operated at $5.6 \pm$ $0.3 \mathrm{~h}^{-1}$ with $\mathrm{N}_{2}, 23 \pm 1^{\circ} \mathrm{C}$ and $50 \pm 5 \%$ relative humidity (RH). The exposed surface area of the VF specimens was $0.0195 \mathrm{~m}^{2}\left(1.9 \mathrm{~m}^{2} \mathrm{~m}^{-3}\right.$ loading $)$. The edges of the specimens were sealed and 
the backs were covered with stainless steel. Because there was evidence that the mass transfer properties of the top were different than the bottom, the top surface of the VF was exposed in one experiment (normal exposure) and the bottom surface in another (reverse exposure). The chamber effluent gas was periodically sampled over a period of 30 days. During the first day, effluent samples were collected at 1, 3, 6 and 24-h elapsed time.

Independent measurements of $\mathrm{C}_{0}$ were obtained using a novel method of cryogenic milling followed by VOC extraction by fluidized bed desorption (FBD) at room temperature. $\mathrm{C}_{0}$ was measured at room temperature because the physical structure of a polymeric material is significantly modified when heated to above its glass transition temperature ( $\mathrm{Tg})$. According to the dual-mobility conceptual model of diffusion in polymers, at temperatures below $\mathrm{Tg}$, one fraction of the total VOC concentration is considered mobile while the other fraction is considered partially immobilized within microvoids frozen into the polymer structure (9). Although additional work is needed to more completely describe the mass transfer characteristics of indoor polymeric materials, $\mathrm{C}_{0}$ determined by $\mathrm{FBD}$ is thought to approximate the mobile fraction of VOCs. The theory, methodology, and equipment used to assess $\mathrm{C}_{0}$ is described elsewhere $(10,11)$. Independent measurements of $\mathrm{K}$ and $\mathrm{D}$ were based on transient sorption/desorption data obtained from tests conducted using a high-resolution dynamic microbalance. The microbalance apparatus and methodology used to determine $\mathrm{K}$ and $\mathrm{D}$ is also described elsewhere $(12,13)$.

Material-phase VOC concentration as a function of depth in the VF samples was measured before and after chamber experiments (11). A microtome was used to cut nine to ten successive thin slivers $(\sim 0.2 \mathrm{~mm}$ thick with a mass of $15-30 \mathrm{mg})$ from a VF specimen. Each VF sliver was transferred to a glass tube which was then inserted into the sleeve heater of a thermal 
desorption apparatus. The inlet flow of humidified $\mathrm{N}_{2}(\sim 10 \% \mathrm{RH})$ to the sample tubes was regulated at $100 \mathrm{~cm}^{3} \mathrm{~min}^{-1}$. A portion of the outlet gas stream (1/25) was sampled for VOCs. The remainder of the flow was vented. At the start of desorption, the heater temperature was quickly ramped from ambient to $60^{\circ} \mathrm{C}$ and held for $10 \mathrm{~min}$. Next, the temperature was ramped over $20 \mathrm{~min}$. to $150^{\circ} \mathrm{C}$ and then held constant. Gas samples were collected successively over periods from 0-60, 60-120 and 120-180 min. after initiating a test. Two replicate tests with blanks were conducted.

A procedure to evaluate $\mathrm{K}_{\mathrm{s}}$, the stainless steel chamber surface/air partition coefficient, was developed. Two 10.5-L stainless steel chambers were connected in series using 0.64-mm Teflon tubing. The chambers were held in an incubator at $23 \pm 1^{\circ} \mathrm{C}$. The first "source" chamber was supplied 1.0 $\pm 0.2 \mathrm{~L} \mathrm{~min}^{-1}$ with nitrogen humidified at $50 \pm 5 \% \mathrm{RH}$. Background samples for the analysis of VOCs were collected from the inlet and outlet of the second "target" chamber. Next, a $15 \times 15-\mathrm{cm}$ square of new VF was attached to a stainless steel plate with the reverse surface exposed. The exposed surface area of the specimen was $0.02 \mathrm{~m}^{2}$. This specimen was placed into the source chamber. VOC samples were collected from the inlet and outlet of the target chamber at 48-h elapsed time. Then, the source chamber was removed. The nitrogen supply gas was connected directly to the inlet of the target chamber, and the flow rate was reduced to $0.46 \pm 0.2 \mathrm{~L} \mathrm{~min}^{-1}$. This established time zero for the decay period. VOC samples were collected from the outlet of the target chamber at average elapsed times of $7.5,20,35,50$, $67.5,90,120,180,270$ and $360 \mathrm{~min}$. The sampling flow rate of $0.10 \mathrm{~L} \mathrm{~min}^{-1}$ was regulated with a mass flow controller. Sample volumes were 0.5-3.0 L. 


\section{Results and Discussion}

Mass Balance. As summarized in Table 1, VOC mass balance calculations were performed by comparing material-phase concentration data collected from VF slivers before and after chamber testing with gas-phase concentration data collected during tests. With the exception of phenol in the reverse exposure tests, VOC mass transfer between the material- and gas-phases balanced within measurement uncertainty. One possible reason for discrepancy is that two different techniques were used to measure the material-phase concentrations. Those measured before the chamber experiment were based on composite samples taken over a larger and different piece of the same VF. The post-chamber measurements were based on a series of ten thin slivers taken over a range of depths from a single point of the exposed VF. Measured material-phase concentrations of phenol in VF show greater variability than the other VOC concentration measurements $(10,11)$. This suggests that phenol is less uniformly distributed in VF than other residual VOCs or that phenol, unlike the alkane hydrocarbons, may be a degradation product of another chemical contained in the VF rather than a manufacturing residual.

Independent Measurement of Model Parameters. The initial material-phase concentration profiles of the four target compounds are shown in Figure 2. The error bars express uncertainty based on the coefficient of variation estimated from concentrations measured in three replicate slivers taken from the VF surface. Although the initial concentrations of n-tetradecane, npentadecane, and phenol are all relatively uniform, the TMPD-MIB concentration varied strongly with depth and could not be used in model validation because Equation 5 requires a uniform initial concentration. Values of the model parameters $\left(\mathrm{C}_{0}, \mathrm{~K}\right.$, and $\left.\mathrm{D}\right)$ for n-pentadecane, n-tetradecane, and phenol are summarized in Table 2. In related work (13) the K and D values of these three compounds were shown to be independent of concentration as required for the model. 
Sink Effect. Values for the stainless steel chamber surface/air partition coefficient, $\mathrm{K}_{\mathrm{s}}$, are also shown in Table 2. These were obtained by plotting the data collected according to Equation 11 (as shown in Figure 3) and then calculating $\mathrm{K}_{\mathrm{s}}$ from the slope of the graph and the known values of $\mathrm{V}, \mathrm{Q}$, and $\mathrm{A}_{\mathrm{s}}$. The plotted data follow linear relationships, supporting the assumption of a rapidly reversible linear adsorption isotherm. In all cases, the magnitude of $\mathrm{K}_{\mathrm{s}} \mathrm{A}_{\mathrm{s}}$ is greater than the magnitude of $\mathrm{V}$, indicating that adsorption is measureable. However, the sink effect made less than $1 \%$ difference in concentrations predicted by the model and was therefore not considered significant in this experimental system.

Validation of Model. Figures 4, 5, and 6 show predicted gas-phase concentrations compared to measured concentrations of n-pentadecane, n-tetradecane, and phenol for the normal and reverse exposure VF chamber experiments. Although the model predicts gas-phase VOC concentrations very well for the reverse exposure scenario, it tends to over-predict for early times and slightly under-predict at longer times. A possible cause of the over-prediction is that $\mathrm{D}$ and $\mathrm{K}$ were measured at $26^{\circ} \mathrm{C}$ while chamber tests were conducted at $23^{\circ} \mathrm{C}$. It has been shown that for VOCs in polymers, $\mathrm{D}$ increases with temperature while $\mathrm{K}$ and decreases with temperature. The model predicts relatively higher gas-phase concentrations as $\mathrm{D}$ grows larger and $\mathrm{K}$ grows smaller. In addition, as previously mentioned, the mass balance for phenol in the reverse exposure experiment indicates lower than expected gas-phase concentrations.

The VOC concentrations from normal exposure VF may be lower than predicted due to different mass transfer properties at the top surface. The steep concentration gradient of TMPDMIB in the VF (Figure 2) suggests that the surface may have been modified during manufacturing. The functionality of the flooring material would presumably be improved by the presence of a low-permeability surface layer. 
Figures 7, 8, and 9 show the measured material-phase concentrations of n-pentadecane, n-tetradecane, and phenol after 722 hours of chamber exposure. The model predicts the material-phase concentrations well, but consistent with the existence of a top surface diffusion barrier, under-predicts the concentrations in normal exposure VF after chamber testing.

Implications for Source Characterization. The good model predictions are very encouraging because the model is based entirely on fundamental mass transfer mechanisms and the model parameters were measured using procedures that were completely independent of the chamber test. This suggests that relatively homogeneous diffusion-controlled building materials can be characterized in a way that is more direct than the traditional chamber study. In addition, the model presented here can also be used to evaluate the impact that indoor materials have on indoor contaminants when acting as a VOC sink $(14,15)$.

The source characterization process would be greatly facilitated if the values of $\mathrm{K}$ and $\mathrm{D}$ could be predicted, as opposed to being measured each time a new contaminant is identified. Although not explored in this paper, the limited results shown in Table 2 suggest that $\mathrm{D}$ and $\mathrm{K}$ tend to correlate with molecular weight and vapor pressure, respectively, as previously suggested (13). If such correlation equations can be deduced for the typical diffusion-controlled materials used in buildings, then all that would be required is the identification and measurement of the initial concentration of individual VOCs in the material-phase. Once the VOCs have been identified and quantified (i.e., $\mathrm{C}_{0}$ is determined), values for $\mathrm{D}$ and $\mathrm{K}$ could be obtained from the correlation equations and used to predict the emission rates without further effort (3).

Future work in this area includes assessing the uniformity of characteristics $\mathrm{K}, \mathrm{D}$, and $\mathrm{C}_{0}$ within a particular material and across different specimens and brands of building materials. Quantifying the temperature dependency of $\mathrm{K}$ and $\mathrm{D}$ is also necessary to maximize the utility of 
the model. Extending this work to other homogenous building materials is needed to further validate the overall strategy. In addition, construction and validation of similar models for nonuniform initial concentrations and multiple-layer building materials would extend the usefulness of the approach.

\section{Acknowledgements}

Financial support for the work at VT was provided by the National Science Foundation (NSF) through an NSF CAREER Award (Grant No. 9624488). Work at LBNL was sponsored by the U.S. Department of Energy, Assistant Secretary for Energy Efficiency and Renewable Energy, Office of Building Technology, State and Community Programs under Contract No. DE-AC0376F00098.

\section{REFERENCES}

1. Tichenor, B.A.; Sparks, L.A.; White, J.B.; and Jackson, M.D. Journal of the Air and Waste Management Association. 1990, 40, 487.

2. Tichenor, B.A.; Sparks, L.A. Indoor Air. 1996, 6, 259.

3. Little, J. C.; Hodgson, A. T. In Characterizing Sources of Indoor Air Pollution and Related Sink Effects; Tichenor, B.A., Ed.; ASTM STP 1287, Philadelphia, U.S.A., 1996; pp 294-304.

4. Little, J. C.; Hodgson, A. T.; Gadgil, A. J. Atmos. Environ. 1994, 28, 227.

5. Cox, S.S., Little, J.C. and Hodgson, A.T. In Proceedings of Healthy Buildings 2000; Espoo, Finland, August 6-10, 2000; SIY Indoor Air Information Oy: Finland, 2000; Vol. 4, pp 169174.

6. Lundgren, B.; Jonsson, B.; Ek-Olausson, B. Indoor Air. 1999, 9, 202.

7. Tshudy, J. A. 1998. Personal communication.

8. ASTM. D 5116-97, Standard Guide for Small-Scale Environmental Chamber Determinations of Organic Emissions From Indoor Materials/Products; American Society for Testing and Materials: West Conshohocken, PA, 1997.

9. Vieth, W. In Diffusion in and Through Polymers; Hanser Publishers: Munich, 1991; pp 29-38.

10. Cox, S.S.; Hodgson, A.T.; Little, J.C. Measuring Concentrations of Volatile Organic Compounds in Vinyl Flooring, Submitted to Journal of the Air and Waste Management Association, 2001.

11. Cox, S.S.; Hodgson, A.T.; Little, J.C. In Proceedings of Engineering Solutions to Indoor Air Quality Problems Symposium; Raleigh, North Carolina, July 17-19, 2000; Air and Waste Management Association: U.S., 2000; pp 65-75. 
12. Zhao, D.Y.; Cox, S.S.; Little, J.C. In Proceedings of the 8th International Conference on Indoor Air Quality and Climate; Edinburgh, Scotland, August 8-13, 1999; Construction Research Communications Ltd.: U.K., 1999; Vol. 1, pp 408-413.

13. Cox, S.S.; Zhao, D.Y.; Little, J.C. Measuring partition and diffusion coefficients of volatile organic compounds in vinyl flooring, Accepted by Atmospheric Environment, 2001.

14. Zhao, D.Y.; Rouques, J.; Little, J.C.; Hodgson, A.T. In Proceedings of the 8th International Conference on Indoor Air Quality and Climate; Edinburgh, Scotland, August 8-13, 1999; Construction Research Communications Ltd.: U.K., 1999; Vol. 5, 264-269.

15. Zhao, D.Y.; Little, J.C.; Hodgson, A.T. Dynamic modeling of the sink effect in response to transient contaminant sources, Submitted to Indoor Air, 2001. 
Table 1. Mass balance summary

\begin{tabular}{|c|c|c|c|c|c|}
\hline Compound & $\begin{array}{c}\text { Measured in } \\
\text { material-phase } \\
\text { pre-chamber }^{\mathrm{a}} \\
\quad(\mu \mathrm{g})\end{array}$ & $\begin{array}{c}\text { Measured in } \\
\text { material-phase } \\
\text { post-chamber }^{\text {a }} \\
(\mu \mathrm{g})\end{array}$ & $\begin{array}{c}\text { Measured } \\
\text { material-phase } \\
\text { loss } \\
(\mu \mathrm{g})\end{array}$ & $\begin{array}{l}\text { Measured in } \\
\text { gas-phase } \\
\text { effluent }^{\mathrm{b}} \\
(\mu \mathrm{g})\end{array}$ & $\begin{array}{c}\text { Difference } \\
(\mu \mathrm{g})\end{array}$ \\
\hline n-pentadecane, $\mathrm{N}$ & $2770 \pm 40$ & $2540 \pm 150$ & 240 & $240 \pm 20$ & 0 \\
\hline n-pentadecane, $\mathrm{R}$ & $2770 \pm 40$ & $2210 \pm 130$ & 560 & $420 \pm 30$ & 140 \\
\hline n-tetradecane, $\mathrm{N}$ & $2530 \pm 40$ & $2320 \pm 200$ & 200 & $270 \pm 20$ & 70 \\
\hline n-tetradecane, $\mathrm{R}$ & $2530 \pm 40$ & $1920 \pm 160$ & 600 & $470 \pm 40$ & 130 \\
\hline phenol, N & $18,600 \pm 900$ & $16,400 \pm 400$ & 2200 & $1800 \pm 120$ & 400 \\
\hline $\begin{array}{l}\text { phenol, R } \\
\mathrm{N} \text { - normal exposure } \\
\mathrm{R} \text { - reverse exposure } \\
{ }^{\mathrm{a}} \text { mean and standard } \\
\mathrm{b} \text { uncertainty based } \mathrm{o}\end{array}$ & $\begin{array}{l}18,600 \pm 900 \\
\text { deviation }\end{array}$ & $13,900 \pm 300$ & 4800 & $2500 \pm 160$ & 2300 \\
\hline
\end{tabular}

Table 2. Model parameters $\mathrm{C}_{0}, \mathrm{~K}, \mathrm{D}$, and $\mathrm{K}_{\mathrm{s}}$ for selected VOCs

\begin{tabular}{|c|c|c|c|c|}
\hline & $\mathbf{C}_{0}{ }^{a}$ & $\mathbf{K}^{\mathbf{a}}$ & $\mathbf{D}^{\mathbf{a}}$ & $\mathbf{K}_{\mathbf{s}}$ \\
\hline Compound & $\left(\mu \mathrm{g} \mathrm{m} \mathbf{m}^{-3}\right)$ & $(-)$ & $\left(\mathrm{m}^{2} \mathrm{~s}^{-1}\right)$ & (m) \\
\hline n-pentadecane & $4.3 \pm 0.9 \times 10^{7}$ & $420,000 \pm 40,000$ & $6.7 \pm 1.1 \times 10^{-14}$ & 0.13 \\
\hline n-tetradecane & $4.4 \pm 0.4 \times 10^{7}$ & $120,000 \pm 1000$ & $1.2 \pm 0.1 \times 10^{-13}$ & 0.043 \\
\hline phenol & $2.0 \pm 0.4 \times 10^{8}$ & $120,000 \pm 3000$ & $1.2 \pm 0.1 \times 10^{-13}$ & 0.065 \\
\hline
\end{tabular}


Figure 1. Schematic representation of a homogenous source in room or chamber

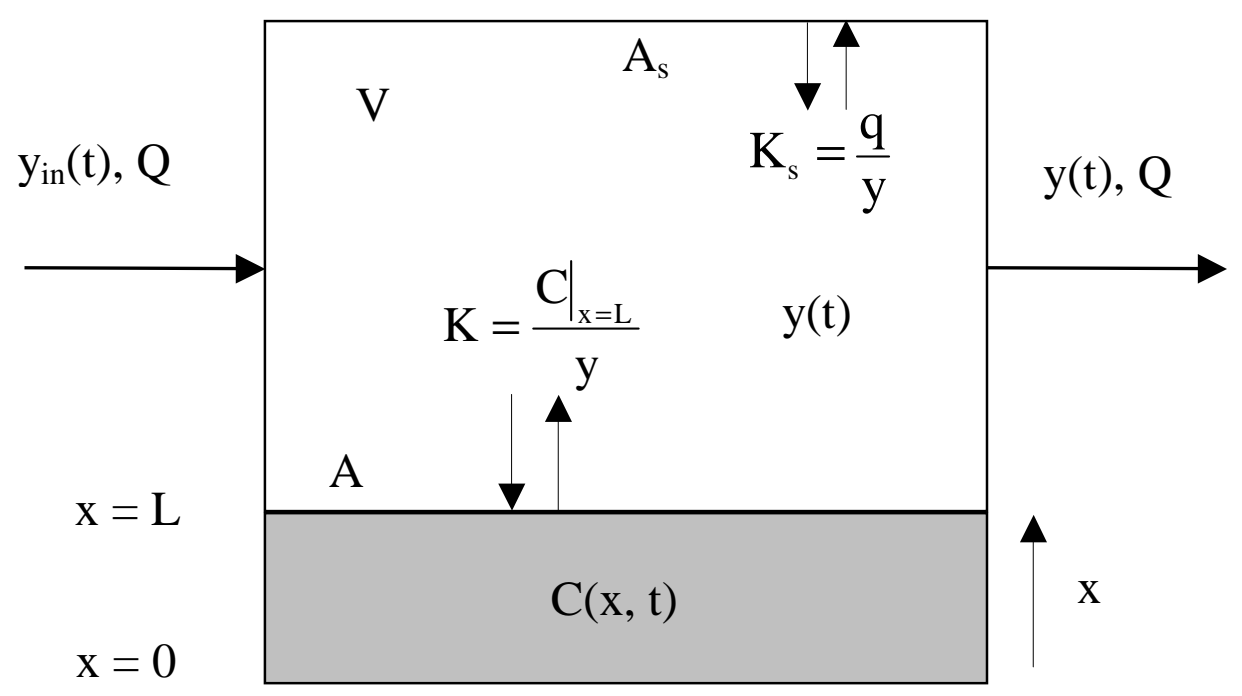


Figure 2. Measured initial material-phase concentration profiles

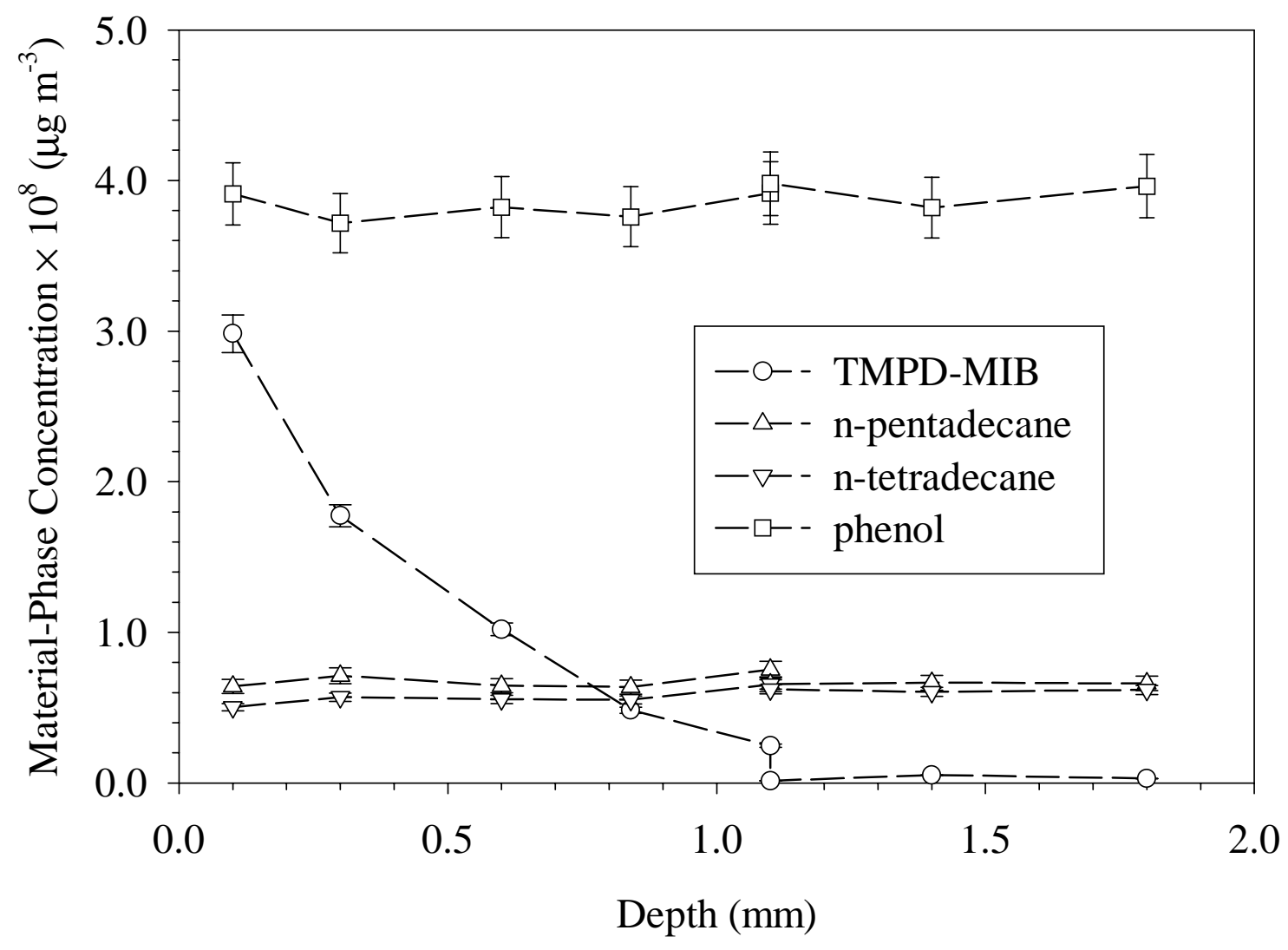


Figure 3. Plot to determine stainless steel chamber surface/air partition coefficients, $\mathrm{K}_{\mathrm{s}}$

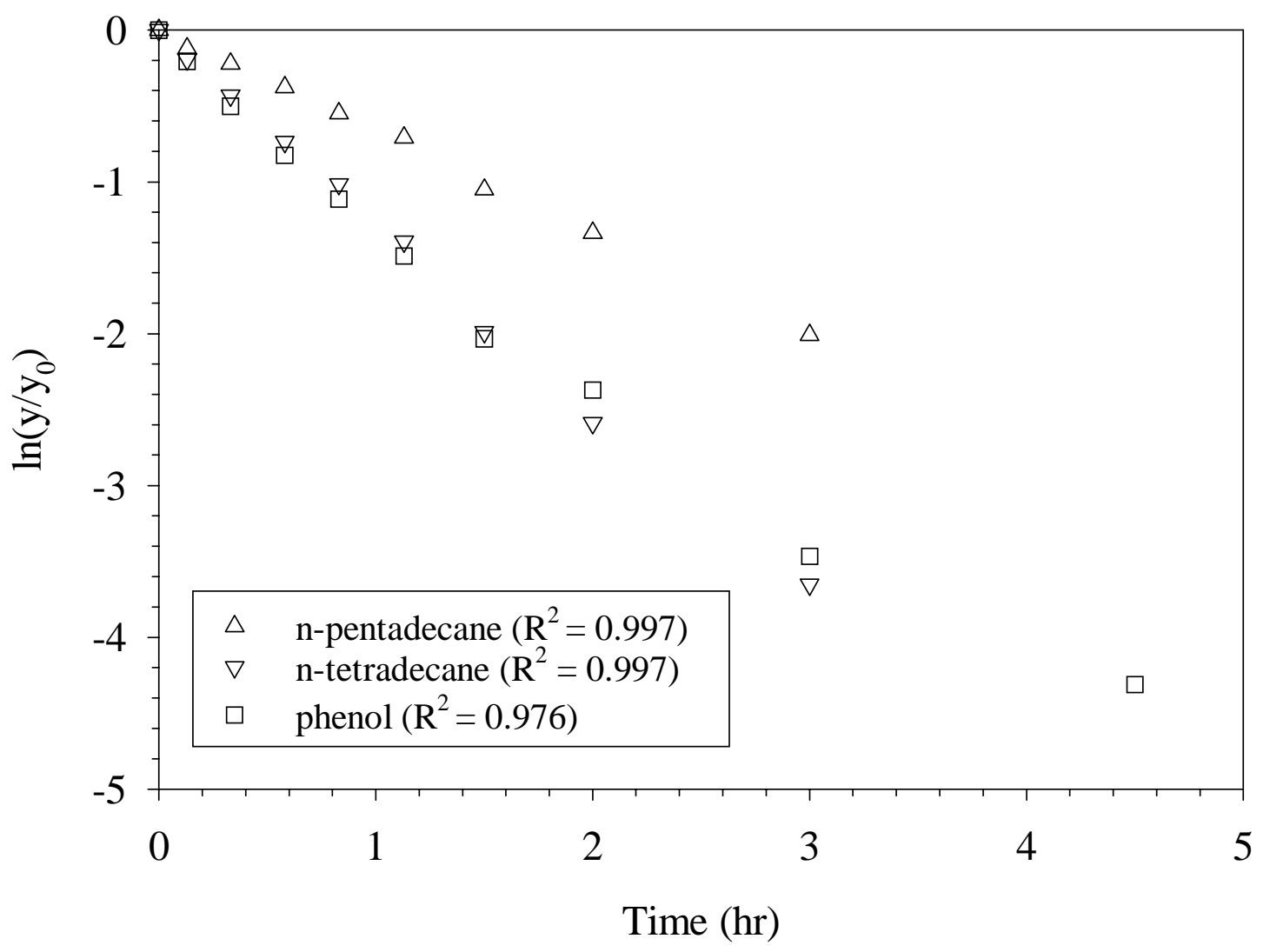


Figure 4. Predicted and measured chamber gas-phase n-pentadecane concentration

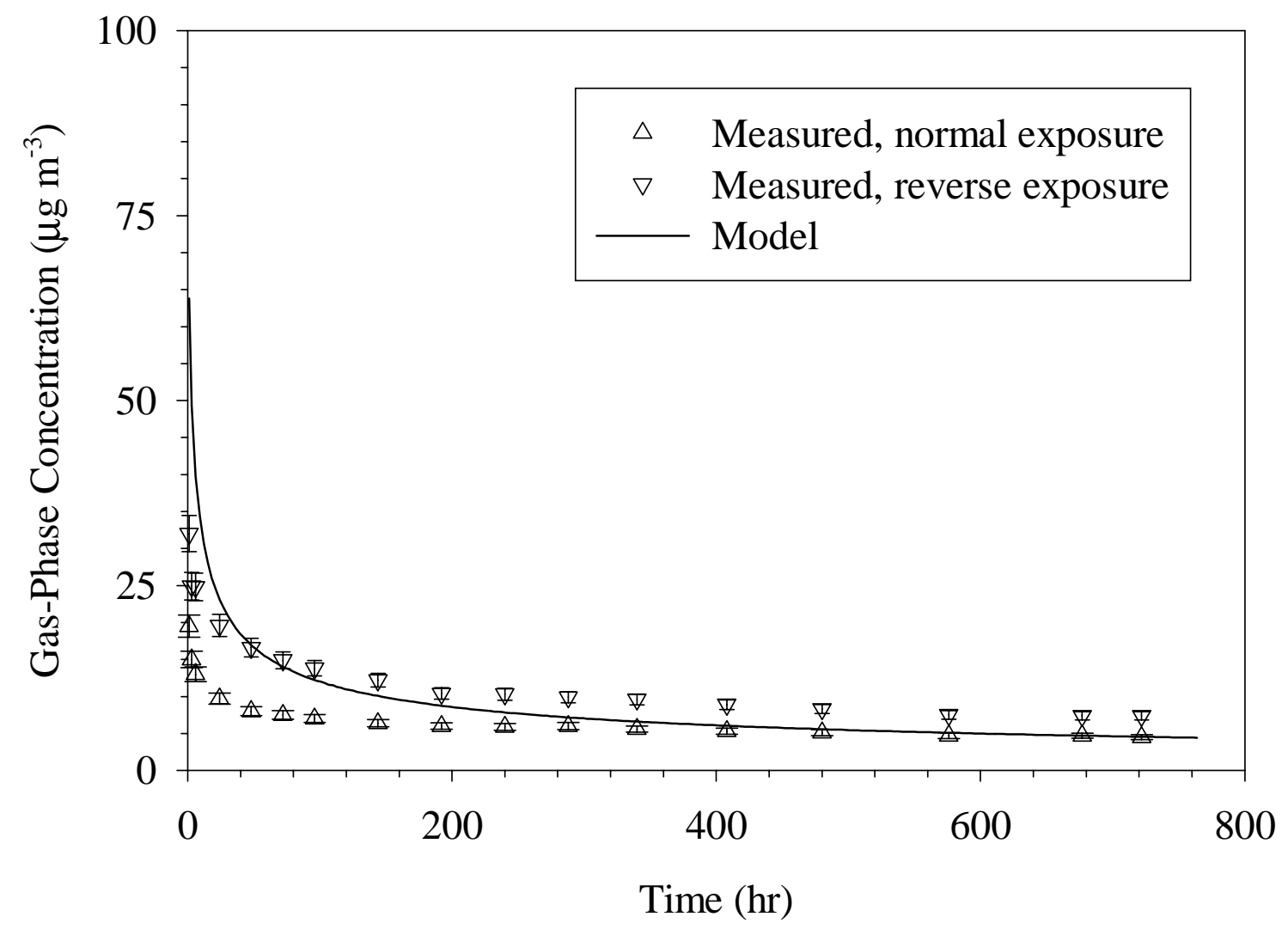


Figure 5. Predicted and measured chamber gas-phase n-tetradecane concentration

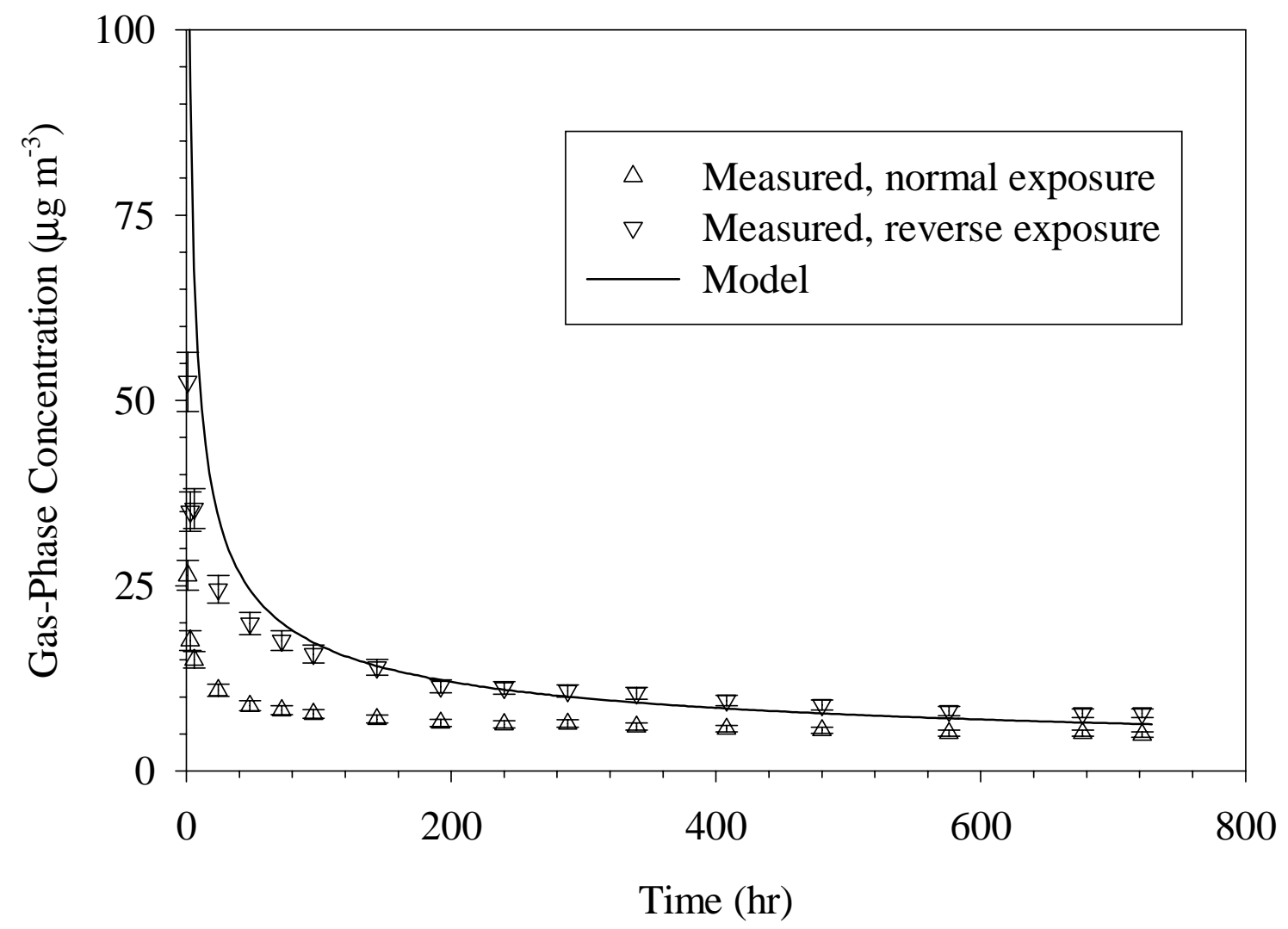


Figure 6. Predicted and measured chamber gas-phase phenol concentration

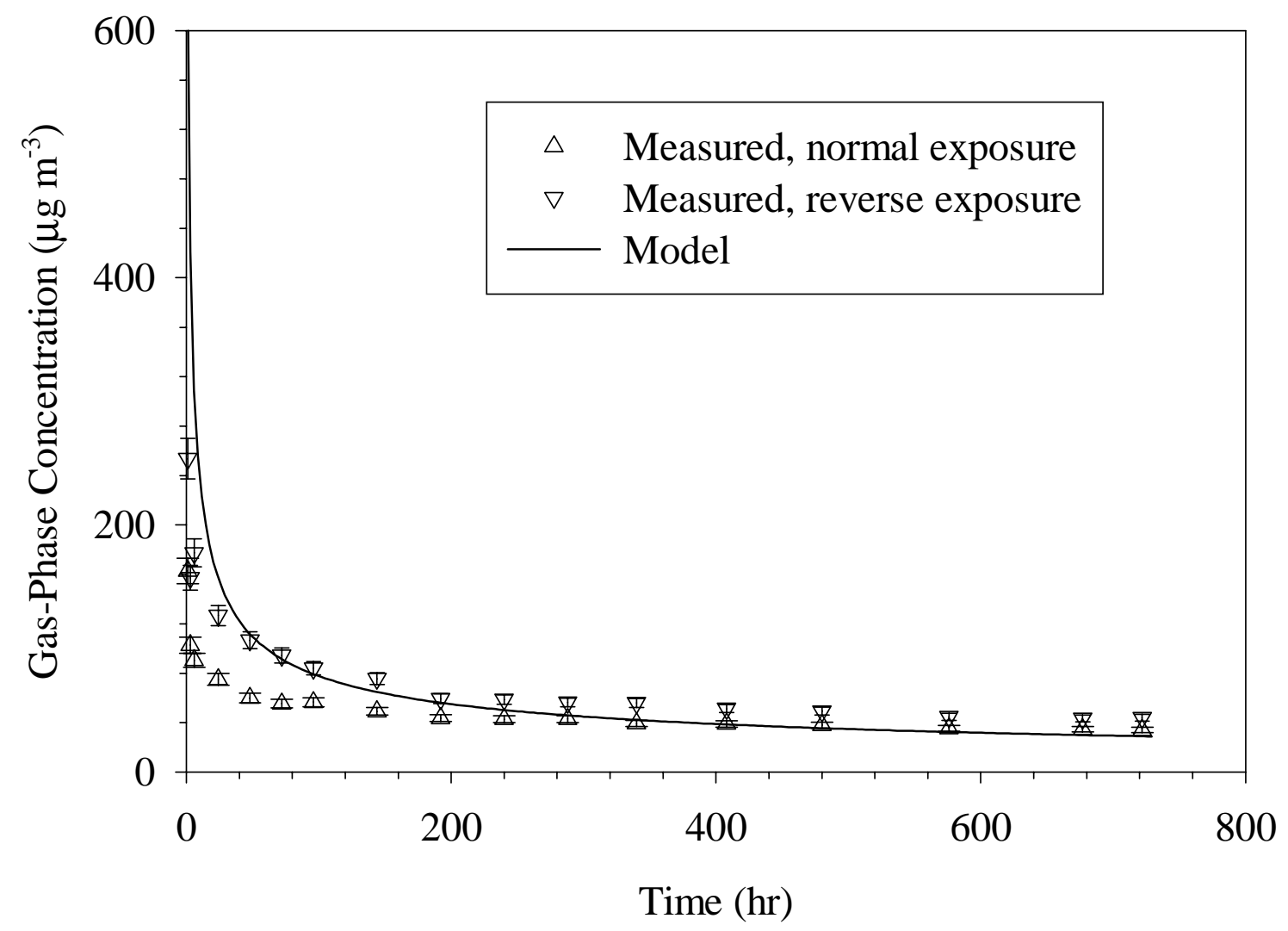


Figure 7. Predicted and measured post-chamber material-phase n-pentadecane concentration profile

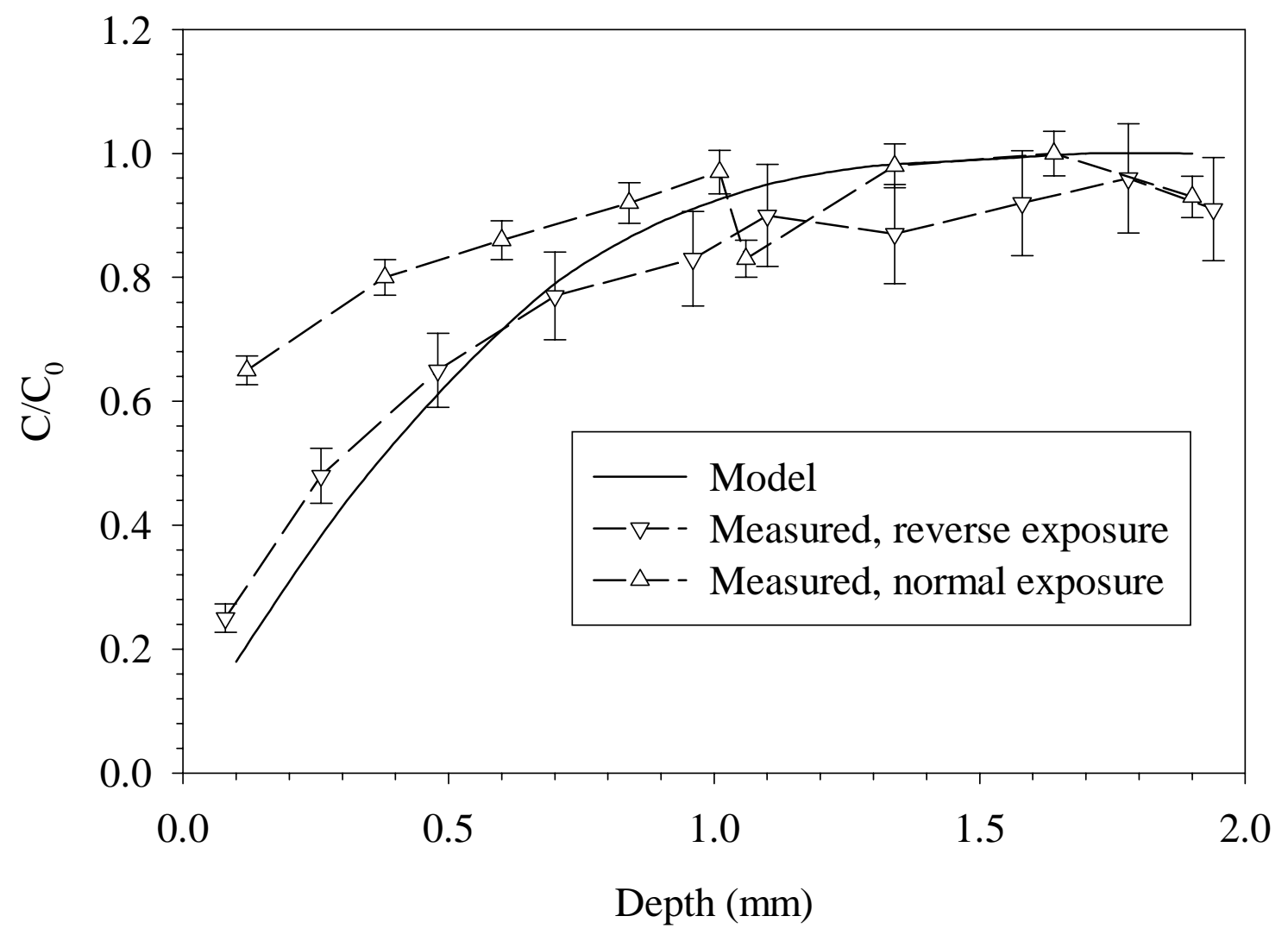


Figure 8. Predicted and measured post-chamber material-phase n-tetradecane concentration profile

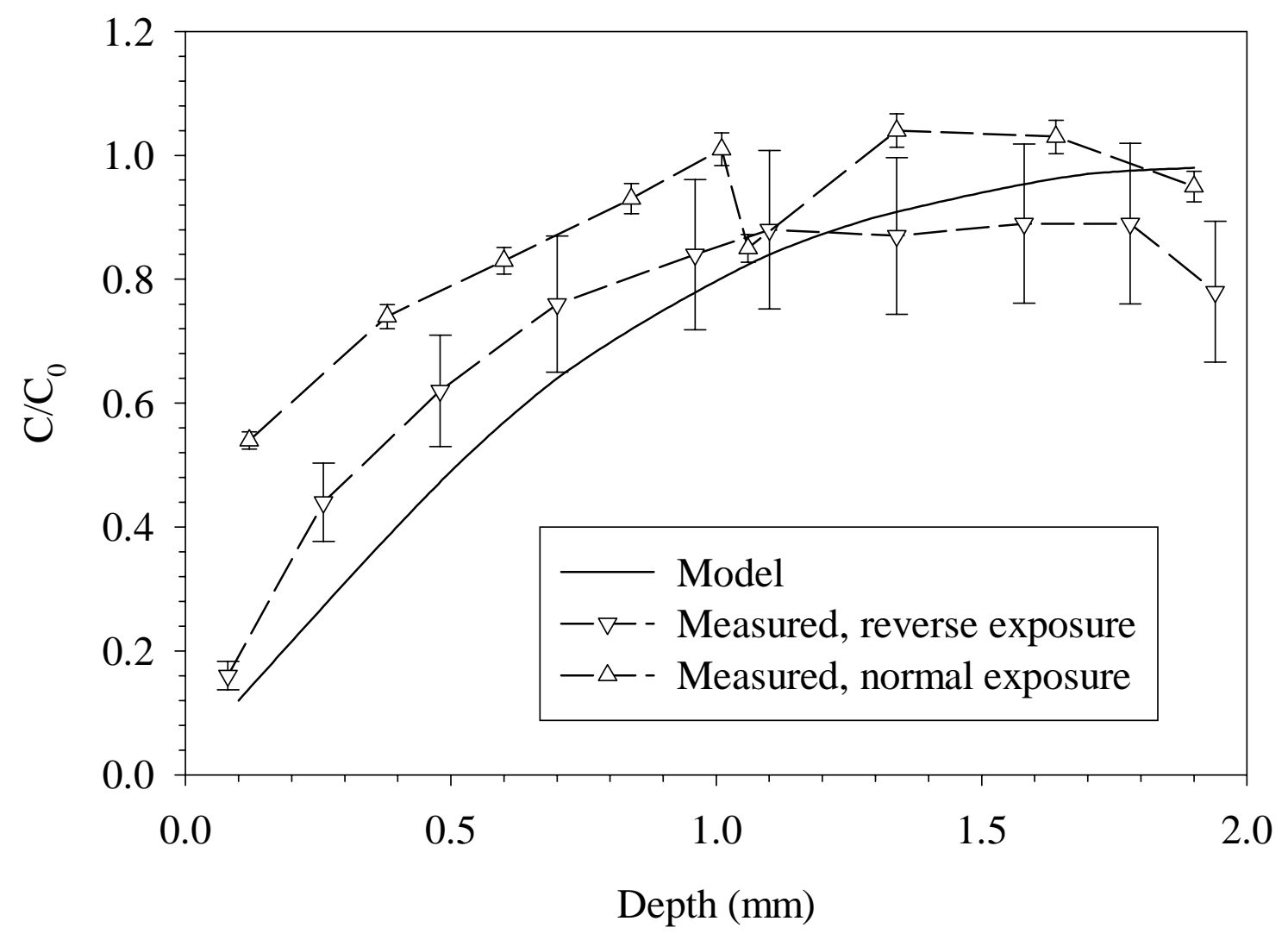


Figure 9. Predicted and measured post-chamber material-phase phenol concentration profile

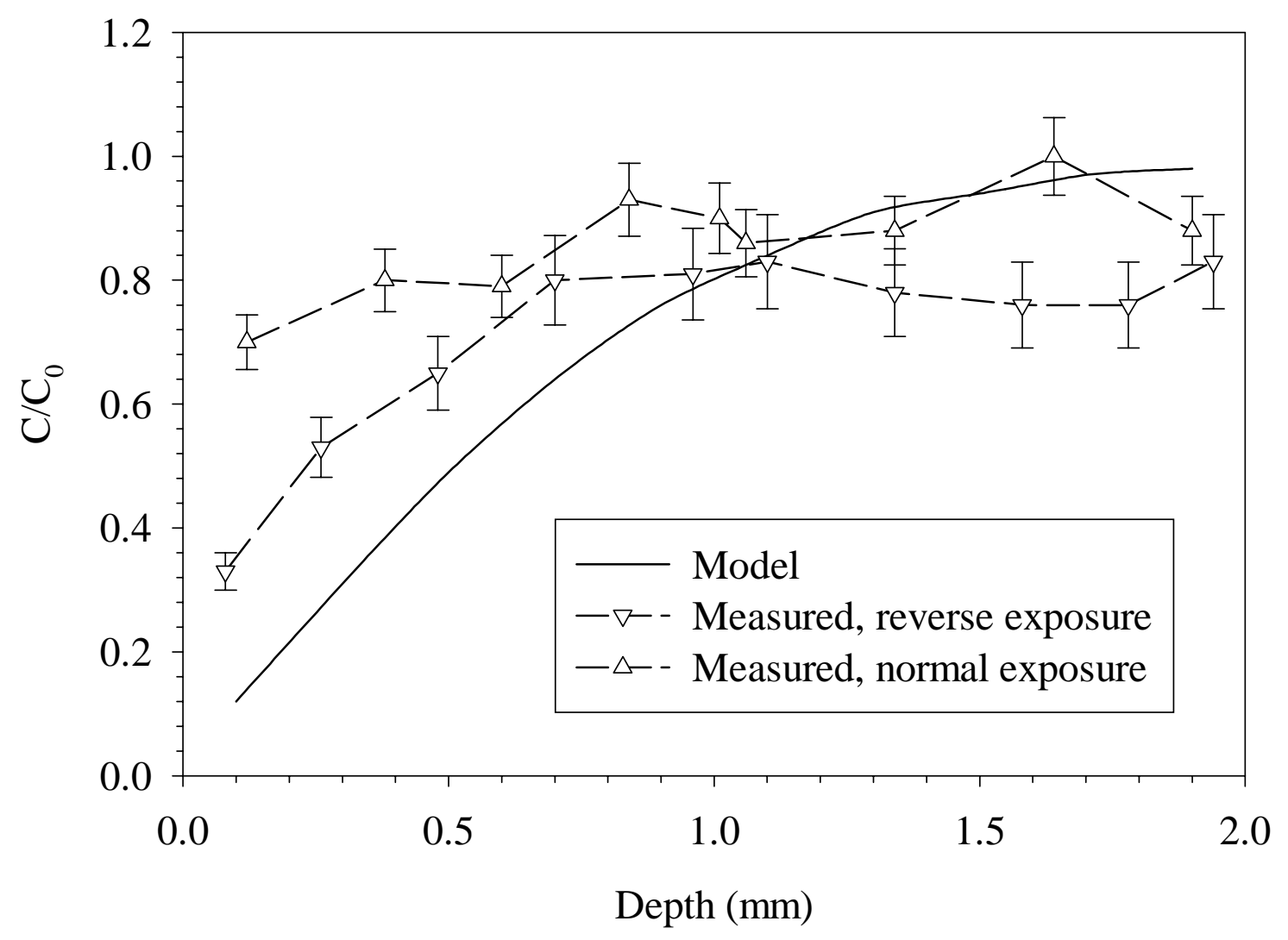

